\title{
EMBEBIC̃̃̃O DE SEMENTES E APLICACÃO FOLIAR COM CLORETO DE MEPIQUAT NO CRESCIMENTO E PRODUÇÃO DO ALGODOEIRO ${ }^{1}$
}

\author{
Soaking seeds and foliar application with mepiquat chloride on growth and yield of cotton plant
}

\author{
Getúlio Takashi Nagashima², Édison Miglioranza³, Celso Jamil Marur ${ }^{4}$, \\ Ruy Seiji Yamaoka ${ }^{5}$, José Carlos Gomes ${ }^{6}$
}

\begin{abstract}
RESUMO
Foi avaliado o efeito do tratamento de sementes de algodão, cultivar IPR 120, embebidas em soluções com cloreto de mepiquat e a interação com a aplicação foliar seqüencial deste produto no crescimento, desenvolvimento e produção de algodão, em condições de campo, em Londrina, PR. O delineamento experimental foi o de blocos casualizados, em esquema fatorial $5 \times 2$, sendo um fator a embebição das sementes com as concentrações de cloreto de mepiquat $[0 ; 0,5 ; 2,5 ; 5$ e 7,5\% (v/v)] e o outro a aplicação foliar (aplicação e não), com quatro repetições. As duas primeiras aplicações foliares ocorreram aos 17 e 32 dias após emergência e as demais a cada 10 dias de intervalo, totalizando sete aplicações. A embebição com regulador afetou a altura da planta, a altura da inserção do nó cotiledonar, não tendo atuação sobre a altura da inserção do primeiro ramo produtivo, número total de ramos, número de ramos frutíferos, número de maçãs por planta e no número de maçãs na primeira posição dos ramos frutíferos, variáveis estas afetadas com aplicação foliar.
\end{abstract}

Termos para indexação: Regulador de crescimento, aplicação parcelada, tratamento de semente, Gossypium hirsutum.

\begin{abstract}
The effect of soaking cotton seeds, cultivar IPR 120, in mepiquat chloride solution and foliar application of such substance on plant height, development and yield of cotton plants were evaluated. The experiment was carried out under field conditions in Londrina, PR, Brazil. Treatments were displayed in a completely randomized design using a random factorial (5X2): five concentrations of mepiquat chloride $(0 ; 0.5 ; 2.5 ; 5.0$ and $7.5 \%(\mathrm{v} / \mathrm{v}))$ for seed soaking and two $\left(0\right.$ and $120 \mathrm{~g}$ i.a.ha $\left.^{-1}\right)$ foliar application, replicated four times. The first two applications were done at 17 and 32 days after emergence, and the remaining five at 10-day intervals. Seed treatment with mepiquat chloride affected plant and cotyledon node heights, but showed no effect on the first productive branch insertion and the total number of branches, reproductive branches, bolls per plant and first position bolls. All these variables were affected by the foliar application.
\end{abstract}

Index terms: Growth regulator, sequential foliar application, seed treatment, Gossypium hirsutum.

(Recebido em 3 de abril de 2006 e aprovado em 26 de janeiro de 2007)

\section{INTRODUÇÃO}

O espaçamento entre linhas do algodoeiro é definido em função da fertilidade do solo, do porte, do hábito de crescimento e também da mecanização, principalmente da colheita. Como regra geral, recomendase que o espaçamento entre linhas do algodoeiro herbáceo seja de $2 / 3$ da altura média das plantas (RIGHI et al., 1965).

Na busca de redução dos custos de produção, altas populações de plantas (obtidas em espaçamentos ultraestreitos) são adotadas nas lavouras, pois este sistema pode levar à diminuição do ciclo da cultura, resultando, ao final, em um número menor de aplicações de insumos.
Ademais, solos considerados marginais (degradados) para esta cultura podem ser mais bem aproveitados adotandose o espaçamento ultra-estreito (ALLEN et al., 1998).

Relatos indicam que pouco é conhecido a respeito de variedades adequadas para produção em espaçamentos ultra-estreitos (WRIGHT et al., 2005). Trabalhos conduzidos na região sudeste dos Estados Unidos da América mostram que muitas variedades precoces ou medianamente precoces, utilizadas em plantios convencionais, podem ser adotadas neste sistema. Os autores citam que estas cultivares, quando manejadas adequadamente, não ramificarão excessivamente e permitirão uma colheita (stripper) mais eficiente.

\footnotetext{
${ }^{1}$ Parte da Dissertação de Mestrado do primeiro autor.

2Doutorando - Departamento de Agronomia - Centro de Ciências Agrárias/CCA - Universidade Estadual de Londrina/UEL - Cx. P. 6001 - 86051 -990 Londrina, PR - gtnagashima@yahoo.com.br

${ }^{3}$ Doutor, Professor, Pesquisador Produtividade CNPq. - Departamento de Agronomia - Centro de Ciências Agrárias/CCA - Universidade Estadual de Londrina/UEL - Cx. P. 6001 - 86051-990 - Londrina, PR - emiglior@uel.br

${ }^{4}$ Doutor, Pesquisador, Área de Ecofisiologia - Instituto Agronômico do Paraná/IAPAR - Rodovia Celso Garcia Cid, Km 375 , Três Marcos - Cx. P. 481 86047-902 - Londrina, PR - cjmarur@iapar.br

${ }^{5}$ Mestre - Área de Fitotecnia - Instituto Agronômico do Paraná/IAPAR - Rodovia Celso Garcia Cid, Km 375, Três Marcos - Cx. P. 481 - $86047-902$ - Londrina, PR yamaoka@iapar.br

${ }^{6}$ Especialização - Área de Biometria - Instituto Agronômico do ParanálIAPAR - Rodovia Celso Garcia Cid, Km 375, Três Marcos - Cx. P.481 - 86047-902 Londrina, PR - jcgomes@iapar.br
} 
Basicamente, para o manejo adequado de uma lavoura nestas condições é imprescindível a utilização de produtos reguladores do crescimento, substâncias químicas sintéticas que alteram o balanço hormonal das plantas. O cloreto de mepiquat (1,1- dimethylpiperidinium chloride) é utilizado tradicionalmente na cultura do algodão inibindo a ação da enzima envolvida na síntese do hormônio giberelina, reduzindo, ao final, a estatura da planta (REDDY et al., 1995).

Ao se proceder à aplicação parcelada do produto, a primeira pulverização pode ser efetuada com botões florais no tamanho de cabeça de alfinete (NICHOLS et al., 2003). Entretanto, as técnicas culturais atualmente disponíveis não impedem que as plantas alcancem estaturas superiores àquelas que seriam indicadas pela recomendação de Righi et al. (1965). Assim, há necessidade de desenvolvimento de tecnologias que permitam a redução do porte da planta o mais cedo possível.

Nagashima et al. (2005) estudaram, em condições de casa-de-vegetação, o efeito do tratamento de sementes de algodão, via embebição, com diferentes concentrações do regulador sintético de crescimento Cloreto de Mepiquat (CM), visando o controle do crescimento da planta já a partir da emergência. As sementes tratadas resultaram em plantas com alturas reduzidas desde a emergência até o início do florescimento, evidenciando a possibilidade de que em condições de campo os tratamentos sejam aplicados satisfatoriamente no adensamento da cultura.

Portanto, buscou-se com este trabalho verificar, em condições de campo, o efeito do tratamento de sementes de algodão embebidas em CM e a sua interação com a aplicação foliar seqüencial deste produto no crescimento, desenvolvimento e produção do algodão.

\section{MATERIAL E MÉTODOS}

O experimento foi realizado em condições de campo, em Londrina, PR (2329'41,4” S, 51¹2'5,5”W). Sementes da cultivar IPR 120 foram embebidas em soluções com cinco doses de CM [0,0; 0,5; 2,5; 5,0 e 7,5\% (v/v)], em 27-11-2003. Foi tratado $0,26 \mathrm{~kg}$ de sementes em $1 \mathrm{~L}$ da solução por tratamento, com a temperatura da água (deionizada) de $24^{\circ} \mathrm{C}$ $\pm 0,5^{\circ} \mathrm{C}$ por 12 horas; em seguida, as sementes foram secas à sombra, e conservadas em sacos de papel por seis dias. Não foi efetuado outro tratamento químico na semente.

A semeadura foi feita no dia 03 de dezembro de 2003 e a emergência ocorreu no dia 09 de dezembro de 2003. O desbaste foi efetuado aos nove dias após emergência (DAE) para atenuar os efeitos da competição intra-específica.
O espaçamento adotado foi de $0,60 \mathrm{~m}$ entre linhas com densidade final de sete plantas por metro linear. Cada parcela foi composta de cinco linhas com cinco metros de comprimento, considerando-se como área útil as três linhas centrais excluindo-se $0,50 \mathrm{~m}$ de cada extremidade.

A adubação de semeadura foi de 15,75 e $75 \mathrm{~kg} \mathrm{ha}^{-1}$ de $\mathrm{N}, \mathrm{P}_{2} \mathrm{O}_{5}$ e $\mathrm{K}_{2} \mathrm{O}$, respectivamente. A adubação nitrogenada em cobertura foi efetuada no estádio $\mathrm{B}_{2}$ (MARUR \& RUANO, 2001), aos 35 DAE, utilizando $40 \mathrm{~kg} \mathrm{ha}^{-1}$ de N na forma de sulfato do amônio.

$\mathrm{O}$ delineamento experimental utilizado foi o de blocos casualizados, arranjados em um esquema fatorial $5 \times 2$, com as cinco concentrações de CM descritas acima e presença ou ausência de aplicações foliares subseqüentes do mesmo produto, com quatro repetições totalizando 40 parcelas.

A aplicação foliar de regulador de crescimento foi iniciada aos 17 DAE (estádio $\mathrm{V}_{3}$ ). A segunda aos 32 DAE (estádio $\mathrm{B}_{1}$ ) e as subseqüentes, efetuadas a cada 10 dias, totalizando sete aplicações. Nas quatro primeiras aplicações usou-se a dose $15 \mathrm{~g}$ i.a.ha ${ }^{-1}$ e nas três últimas 20 g i.a.ha-1 . Foi utilizado pulverizador costal de $\mathrm{CO}_{2}$, com volume de aplicação de $333 \mathrm{~L} \mathrm{ha}^{-1}$ com um gasto total de $120 \mathrm{~g} \mathrm{ha}^{-1}$ do produto técnico por tratamento.

O controle das plantas daninhas foi realizado por meio de capinas manuais e para o controle de pragas foram aplicados tratamentos normalmente recomendados para esta cultura.

Foram marcadas dez plantas na linha central da parcela, onde foram monitorados as alturas, medidas do nível do solo ao ápice da planta, e os estádios fenológicos aos 10, 17, 24, 31, 56, 86 e 116 DAE. A área foliar estimada (NAGASHIMA et al., 2005), massa da matéria seca de folhas, caules e estruturas reprodutivas foram mensuradas nas fases $\mathrm{B}_{1}, \mathrm{~F}_{1}$, "Cutout" (paralisação do crescimento vegetativo) e $C_{1}$ (MARUR \& RUANO, 2001), aos 31, 56, 86 e 116 DAE respectivamente, sendo retiradas duas plantas por repetição, da segunda e quarta linhas de cada parcela e as partes foram embaladas em sacos de papel e secos em estufa com circulação forçada de ar, mantida à temperatura constante de $60^{\circ} \mathrm{C}$, até a obtenção de massa constante.

Por ocasião da primeira colheita, aos $130 \mathrm{DAE}$, foram coletados 20 capulhos situados no terço médio, das segunda e quarta linhas para determinação da sua massa. Foram colhidos os capulhos de quatro metros da linha central, eliminando meio metro de cada extremidade. Nesta ocasião foi medida a altura da inserção do nó cotiledonar, do primeiro ramo produtivo, e contado o número total de 
ramos por planta, número de ramos produtivos, número de maçãs por planta e o número de maçãs na posição um dos ramos frutíferos. A segunda e última colheita foi efetuada aos 156 DAE.

Os dados foram submetidos à análise de variância e ao teste Tukey ao nível de 5\% de probabilidade aplicados no fator com níveis qualitativos e análise de regressão no com níveis quantitativos.

\section{RESULTADOS E DISCUSSÃO}

Para a variável altura, constata-se que houve diferença entre as doses de CM na embebição das sementes de algodão até os 31 DAE (Tabela 1). Estes efeitos também foram notados por Corbin \& Frans (1991), que testaram o uso de $\mathrm{CM}$ e cloreto de clormequat no tratamento para reduzir o efeito negativo de Fluometuron e constataram que a altura das plantas foi reduzida até três semanas após semeadura, com recuperação do crescimento dessas plantas até nove semanas após o plantio.
Não houve efeito interativo entre a aplicação foliar e embebição de sementes (Tabela 1). Como as doses de $\mathrm{CM}$ utilizadas nas primeiras aplicações foliares foram baixas, $15 \mathrm{~g}$ i.a. ha ${ }^{-1}$, não resultaram em adicional redução da estatura das plantas oriundas dos tratamentos com embebição de sementes, e permitiram a recuperação e uniformização do crescimento.

A aplicação foliar apresentou-se efetiva a partir dos 24 DAE, com o efeito persistindo até o final do ciclo da cultura (Tabela 1). Ao final, os tratamentos com aplicação foliar reduziram a altura das plantas em $28 \%$ (Tabela 2), confirmando os resultados obtidos por Athayde \& Lamas (1999), Furlani Junior et al. (2003), Laca-Buendia (1989), Lamas (2001) e Nichols et al. (2003).

A embebição de sementes de algodão em soluções com concentrações de $\mathrm{CM}$ reduziu efetivamente o crescimento das plantas nas primeiras semanas (em até $26,1 \%$ para a dose de $7,5 \%$ ), apresentando comportamentos lineares significativos para 10, 17, 24 e 31 DAE, e não apresentando significância nas demais avaliações (Figura 1).

TABELA 1 - Análise de variância referente à altura de plantas de algodão originadas de sementes embebidas em solução de cloreto de mepiquat aos 10, 17, 24, 31, 56, 86 e 116 dias após emergência e na presença e ausência de aplicação foliar seqüencial via foliar. Londrina, PR, 2004.

\begin{tabular}{lcccccccc}
\hline \multirow{2}{*}{ Causas da variação } & \multicolumn{7}{c}{ Quadrado médio } \\
\cline { 2 - 9 } & G.L. & 10 DAE & 17 DAE & 24 DAE & 31 DAE & 56 DAE & 86 DAE & 116 DAE \\
\hline Dose (D) & 4 & $11,31^{* *}$ & $15,43^{* *}$ & $29,70^{* *}$ & $24,05^{*}$ & $24,73 \mathrm{~ns}$ & $9,20 \mathrm{~ns}$ & $30,75 \mathrm{~ns}$ \\
Aplicação foliar (AF) & 1 & $0,00 \mathrm{~ns}$ & $0,25 \mathrm{~ns}$ & $23,82^{* *}$ & $68,07^{* *}$ & $1899,71^{* *}$ & $6436,91^{* *}$ & $7360,37 * *$ \\
D X AF & 4 & $0,56 \mathrm{~ns}$ & $1,56 \mathrm{~ns}$ & $1,70 \mathrm{~ns}$ & $4,14 \mathrm{~ns}$ & $12,27 \mathrm{~ns}$ & $20,53 \mathrm{~ns}$ & $58,02 \mathrm{~ns}$ \\
Blocos & 3 & $5,27 \mathrm{~ns}$ & $7,58 \mathrm{~ns}$ & $16,61 \mathrm{~ns}$ & $20,09 \mathrm{~ns}$ & $54,23 \mathrm{~ns}$ & $182,95 \mathrm{~ns}$ & $214,95 \mathrm{~ns}$ \\
\hline
\end{tabular}

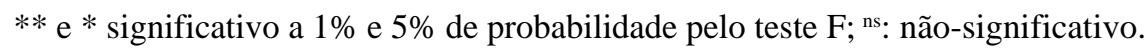

TABELA 2 - Altura média (cm) de plantas de algodão aos 10, 17, 24, 31, 56, 86 e 116 dias após emergência (DAE) na presença e ausência de aplicações foliares seqüenciais de cloreto de mepiquat. Londrina, PR, 2004.

\begin{tabular}{ccccc}
\hline $\begin{array}{c}\text { Dias após } \\
\text { emergência (DAE) }\end{array}$ & Ausência & Presença & DMS & C.V. (\%) \\
\hline 10 & $7,45 \mathrm{a}^{(1)}$ & $7,45 \mathrm{a}$ & 0,57 & 11,57 \\
17 & $11,14 \mathrm{a}$ & $10,98 \mathrm{a}$ & 0,71 & 9,87 \\
24 & $19,87 \mathrm{a}$ & $18,32 \mathrm{~b}$ & 1,06 & 8,59 \\
31 & $26,91 \mathrm{a}$ & $24,30 \mathrm{~b}$ & 1,62 & 9,73 \\
56 & $72,36 \mathrm{a}$ & $58,59 \mathrm{~b}$ & 3,10 & 7,28 \\
86 & $93,18 \mathrm{a}$ & $67,81 \mathrm{~b}$ & 5,80 & 11,11 \\
116 & $96,50 \mathrm{a}$ & $69,37 \mathrm{~b}$ & 5,89 & 10,93 \\
\hline
\end{tabular}

${ }^{(1)}$ Médias seguidas de mesma letra na linha, não diferem entre si pelo teste de Tukey a 5\% de probabilidade. 
Ao se avaliar a altura da inserção do nó cotiledonar, no estádio fenológico $\mathrm{C}_{1}$, constatou-se o efeito da embebição de sementes, comprovando que as diferenças nas alturas observadas refletiram-se linearmente naquela variável, com significativa redução (Figura 2). Por outro lado, a aplicação foliar do regulador de crescimento não apresentou efeito sobre a altura da inserção do nó cotiledonar.

As variáveis massas da matéria seca de folhas, de caules e de aparelhos reprodutivos, peso de capulho, produção de algodão em caroço, número de maçãs por planta e maçãs na posição 1 estão apresentadas na Tabela 3.

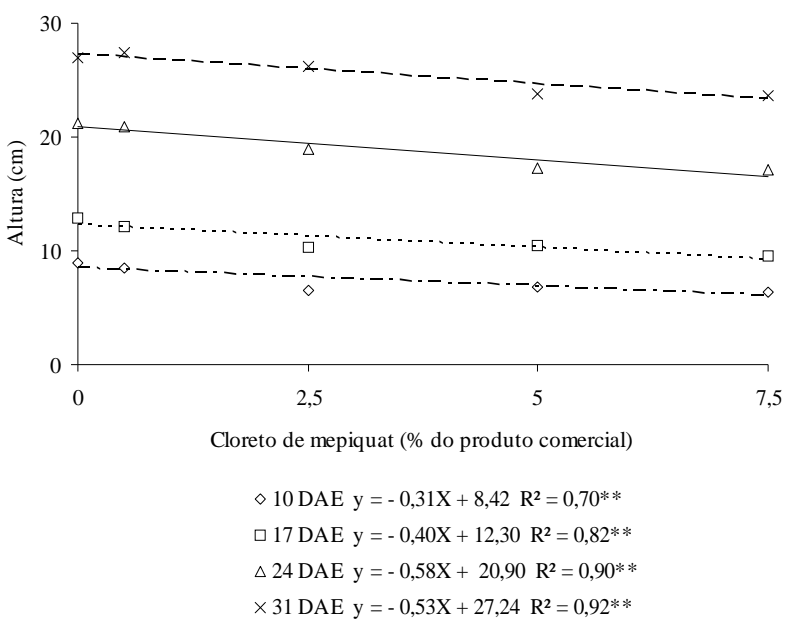

FIGURA 1 - Altura média de plantas de algodoeiro originadas de sementes embebidas em solução de cloreto de mepiquat, aos 10, 17, 24, 31 dias após emergência, em função das doses. Londrina, PR, 2004.

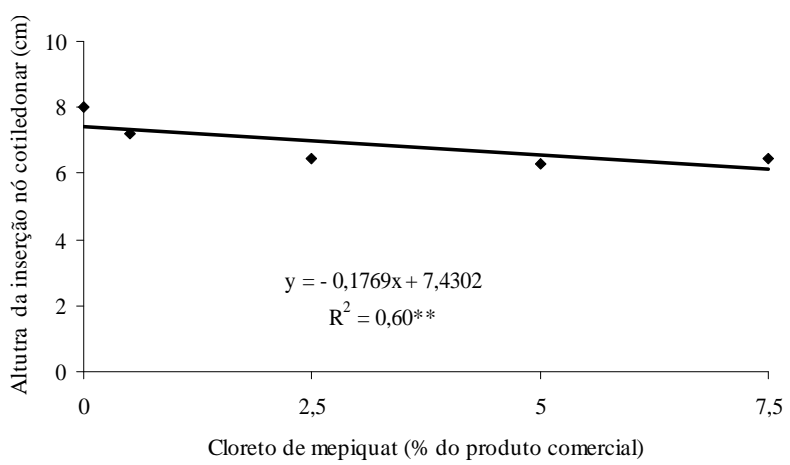

FIGURA 2 - Altura média da inserção do nó cotiledonar em plantas de algodoeiro originadas de sementes embebidas em solução com deferentes concentrações de cloreto de mepiquat nas doses de $0 ; 0,5 ; 2,5 ; 5$ e 7,5\% aos 116 dias após emergência. Londrina, PR, 2004.
Houve diferença para as aplicações foliares, reduzindo a altura da inserção do primeiro ramo produtivo, diminuindo o número total de ramos por planta e o número de ramos frutíferos (Tabela 4). Demonstra-se assim que a diminuição no porte não é resultado somente do encurtamento de internódios, mas também da redução do número de ramos por planta. Este resultado não difere dos obtidos por Mondino \& Peterlin (2002) e Nichols et al. (2003), e é discordante, no entanto, dos resultados obtidos por Laca-Buendia (1989), que aplicando Pix e Cycocel em diversas dosagens, em aplicação única e parcelada, não observaram diferenças estatísticas no número de ramos.

Não houve efeito tanto da embebição da semente quanto das aplicações foliares seqüenciais no peso de capulho (Tabela 3). Athayde \& Lamas (1999) e Laca-Buendia (1989) também não verificaram efeito de aplicações do produto sobre este componente da produção, enquanto que Lamas (2001) observou maior massa seca do capulho com aplicação de reguladores de crescimento. O número de maçãs por planta, número de maçãs na posição um não foram afetadas pelo tratamento de semente através de embebição com CM (Tabelas 3 e 4). A frutificação nesta posição é importante, pois representa $65 \%$ da produção (KERBY et al., 1986; ROSOLEN, 2001). Não houve efeito das aplicações foliares para a produção, porém para número de maçãs por planta e para número de maçãs na posição um (Tabelas 3 e 4), houve redução, diferindo do obtido por Laca-Buendia (1989) que apresentou diferença na produção com o uso de Pix na dose de 50 g i.a.ha ${ }^{-1}$.

A produção de algodão em caroço não apresentou diferenças significativas na embebição de sementes (Tabela 5) e não apresentou diferença entre a aplicação e não de reguladores via foliar (Tabela 3). Yeats et al. (2005) observaram detrimento na produção embebendo semente com doses maiores que $4 \mathrm{~g} \mathrm{MC} / \mathrm{kg}$ de semente, cultivadas em condições de espaçamento convencional (0,80 e 1,0 m). No período de 1979 a 1983, Kerby (1985) não encontrou diferença significativa para a produção nas parcelas com uso de regulador de crescimento, via foliar comparada com parcelas não aplicadas, comprovando que o regulador não é aplicado para aumentar a produção, mas para manter satisfatória a altura de plantas em solos com alta fertilidade (HODGES et al., 1991). 
TABELA 3 - Análises de variância referentes à massa da matéria seca de folhas e caules aos 31, 56, 86 e 116 DAE, massa da matéria seca de estruturas reprodutivas aos 56, 86 e 116 DAE, peso de capulho, produção de algodão em caroço, número de maçãs por planta e número de maças na posição 1 aos 116 DAE. Londrina, PR, 2004.

\begin{tabular}{|c|c|c|c|c|}
\hline \multicolumn{5}{|c|}{ Quadrado médio } \\
\hline & Dose & Aplicação foliar & Dose $x$ apl. foliar & blocos \\
\hline $\begin{array}{l}\text { Graus de } \\
\text { liberdade }\end{array}$ & 4 & 1 & 4 & 3 \\
\hline \multicolumn{5}{|c|}{ Variáveis } \\
\hline \multicolumn{5}{|c|}{ Massa da matéria seca de folhas } \\
\hline $31 \mathrm{DAE}$ & $0,51 \mathrm{~ns}$ & $0,23 \mathrm{~ns}$ & $0,07 \mathrm{~ns}$ & $0,36 \mathrm{~ns}$ \\
\hline $56 \mathrm{DAE}$ & $2,18 \mathrm{~ns}$ & $31,33 *$ & $6,61 \mathrm{~ns}$ & $2,20 \mathrm{~ns}$ \\
\hline $86 \mathrm{DAE}$ & $11,01 \mathrm{~ns}$ & $72,60 \mathrm{~ns}$ & $29,77 \mathrm{~ns}$ & $2,82 \mathrm{~ns}$ \\
\hline $116 \mathrm{DAE}$ & $48,08 \mathrm{~ns}$ & $241,62 \mathrm{~ns}$ & $22,96 \mathrm{~ns}$ & $27,19 \mathrm{~ns}$ \\
\hline \multicolumn{5}{|c|}{ Massa da matéria seca de caules } \\
\hline $31 \mathrm{DAE}$ & $0,52 *$ & $0,83 *$ & $0,13 \mathrm{~ns}$ & $0,08 \mathrm{~ns}$ \\
\hline $56 \mathrm{DAE}$ & $5,79 \mathrm{~ns}$ & $127,66 * *$ & $10,95 \mathrm{~ns}$ & $4,49 \mathrm{~ns}$ \\
\hline $86 \mathrm{DAE}$ & $67,78 \mathrm{~ns}$ & $1301,11 * *$ & $88,40 \mathrm{~ns}$ & $16,39 \mathrm{~ns}$ \\
\hline $116 \mathrm{DAE}$ & $108,05 \mathrm{~ns}$ & $6077,46 * *$ & $26,42 \mathrm{~ns}$ & $67,38 \mathrm{~ns}$ \\
\hline \multicolumn{5}{|c|}{ Massa da matéria seca de estruturas reprodutivas } \\
\hline $56 \mathrm{DAE}$ & $0,43 \mathrm{~ns}$ & $0,36 \mathrm{~ns}$ & $0,25 \mathrm{~ns}$ & $0,32 \mathrm{~ns}$ \\
\hline 86 DAE & $72,41 \mathrm{~ns}$ & $111,59 *$ & $17,06 \mathrm{~ns}$ & $23,13 \mathrm{~ns}$ \\
\hline $116 \mathrm{DAE}$ & $809,61 \mathrm{~ns}$ & $1146,29 \mathrm{~ns}$ & $376,66 \mathrm{~ns}$ & $654,60 \mathrm{~ns}$ \\
\hline \multicolumn{5}{|c|}{ Peso de capulho } \\
\hline & $0,06 \mathrm{~ns}$ & $0,26 \mathrm{~ns}$ & $0,01 \mathrm{~ns}$ & $0,03 \mathrm{~ns}$ \\
\hline \multicolumn{5}{|c|}{ Produção de algodão em caroço } \\
\hline & $930,90 \mathrm{~ns}$ & $152,69 \mathrm{~ns}$ & $502,50 \mathrm{~ns}$ & $2235,04 \mathrm{~ns}$ \\
\hline \multicolumn{5}{|c|}{ Número de maçãs por planta } \\
\hline & $2,97 \mathrm{~ns}$ & $8,28 *$ & $1,88 \mathrm{~ns}$ & $4,64 \mathrm{~ns}$ \\
\hline \multicolumn{5}{|c|}{ Número de maças na posição 1} \\
\hline & $29,68 \mathrm{~ns}$ & $343,98 *$ & $62,16 \mathrm{~ns}$ & $180,05 \mathrm{~ns}$ \\
\hline
\end{tabular}

ns: não-significativo ; * e $* *$ : significativos a $5 \%$ e $1 \%$ de probabilidade pelo teste $\mathrm{F}$.

TABELA 4 - Altura da inserção do nó cotiledonar, da inserção do $1^{\circ}$ ramo produtivo, número total de ramos, de ramos produtivos, número de maçãs por planta e de maçãs na posição 1 com presença e ausência da aplicação foliar seqüencial de cloreto de mepiquat aos 116 dias após emergência. Londrina, PR, 2004.

\begin{tabular}{lcccr}
\hline \multicolumn{1}{c}{ Variáveis } & Ausência & Presença & DMS & C.V. $(\%)$ \\
\hline Altura da inserção nó cotiledonar & $7,04 \mathrm{a}^{(1)}$ & $6,73 \mathrm{a}$ & 0,36 & 8,09 \\
Altura da inserção do $1^{\circ}$ ramo & $30,79 \mathrm{a}$ & $27,88 \mathrm{~b}$ & 1,98 & 10,38 \\
produtivo & & & & 6,28 \\
Total de ramos & $16,74 \mathrm{a}$ & $15,00 \mathrm{~b}$ & 0,65 & 9,73 \\
Número de ramos produtivos & $11,18 \mathrm{a}$ & $9,77 \mathrm{~b}$ & 0,66 & 14,76 \\
Número de maçãs por planta & $9,30 \mathrm{a}$ & $8,39 \mathrm{~b}$ & 0,85 & 12,66 \\
Número de maçãs na posição 1 & $7,38 \mathrm{a}$ & $6,79 \mathrm{~b}$ & 0,58 & \\
\hline
\end{tabular}

${ }^{(1)}$ Médias seguidas de mesma letra na linha, não diferem entre si pelo teste de Tukey a $5 \%$ de probabilidade. 
TABELA 5 - Produção média de algodão em caroço obtidas de plantas originadas de sementes embebidas em solução de cloreto de mepiquat $(0 ; 0,5 ; 2,5 ; 5$ e 7,5\% do produto comercial). Londrina, PR, 2004.

\begin{tabular}{cc}
\hline Concentração & Produção $\left(@ \mathbf{h a}^{-\mathbf{1}}\right)$ \\
\hline $0 \%$ & $306,81 \mathrm{a}$ \\
$0,5 \%$ & $330,19 \mathrm{a}$ \\
$2,5 \%$ & $313,56 \mathrm{a}$ \\
$5,0 \%$ & $303,96 \mathrm{a}$ \\
$7,5 \%$ & $321,39 \mathrm{a}$ \\
\hline DMS & 40,80 \\
C.V.(\%) & 8,86 \\
\hline
\end{tabular}

Médias seguidas de mesma letra na coluna não diferem entre si pelo teste de Tukey ao nível de $5 \%$.
A massa da matéria seca de folhas obtida aos 31, 56,86 e 116 DAE não foi afetada pelos tratamentos de embebição de sementes. A aplicação foliar do regulador de crescimento reduziu a massa da matéria seca de folhas aos 56 DAE não apresentando efeito aos 31, 86 e 116 DAE (Tabela 6). Não houve efeito das doses na embebição de sementes para massa da matéria seca de caules e estruturas reprodutivas, com exceção para a massa da matéria seca de caules aos 31 DAE que apresentou diferença significativa entre a concentração de $5,0 \%$ e $0 \%$. As aplicações foliares reduziram significativamente a massa da matéria seca do caule em todo o período analisado (Tabela 6), corroborando os resultados obtidos por Athayde \& Lamas (1999). Para a variável massa da matéria seca das estruturas reprodutivas, houve diferença significativa somente aos 116 DAE, com redução de 9,8\% (Tabela 6).

TABELA 6 - Média da massa da matéria seca (g) de folhas, caules e estruturas reprodutivas, aos 31, 56, 86 e 116 dias após emergência, com presença e ausência de aplicação foliar seqüencial de cloreto de mepiquat. Londrina, PR, 2004.

\begin{tabular}{|c|c|c|c|c|c|}
\hline Variáveis & & Ausência & Presença & DMS & C.V. $(\%)$ \\
\hline \multirow{2}{*}{$31 \mathrm{DAE}$} & Folhas & $2,35 \mathrm{a}^{(1)}$ & $2,20 \mathrm{a}$ & 0,28 & 19,27 \\
\hline & Cules & $1,49 \mathrm{a}$ & $1,20 \mathrm{~b}$ & 0,26 & 29,33 \\
\hline \multirow{3}{*}{$56 \mathrm{DAE}$} & Folhas & $13,53 a$ & $11,76 b$ & 1,40 & 17,01 \\
\hline & Caules & $15,12 \mathrm{a}$ & $11,54 b$ & 1,76 & 20,33 \\
\hline & $\begin{array}{l}\text { Estruturas } \\
\text { reprodutivas }\end{array}$ & $1,64 \mathrm{a}$ & $1,45 \mathrm{a}$ & 0,32 & 32,41 \\
\hline \multirow{3}{*}{$86 \mathrm{DAE}$} & Folhas & $20,60 \mathrm{a}$ & $17,91 \mathrm{a}$ & 2,90 & 23,21 \\
\hline & Caules & $35,37 \mathrm{a}$ & $23,97 b$ & 4,78 & 24,91 \\
\hline & $\begin{array}{l}\text { Estruturas } \\
\text { reprodutivas }\end{array}$ & $26,96 a$ & $23,62 a$ & 3,37 & 20,53 \\
\hline \multirow{3}{*}{$116 \mathrm{DAE}$} & Folhas & $28,45 a$ & $23,53 a$ & 5,10 & 30,22 \\
\hline & Caules & $62,28 \mathrm{a}$ & $37,62 b$ & 6,95 & 21,44 \\
\hline & $\begin{array}{l}\text { Estruturas } \\
\text { reprodutivas }\end{array}$ & $108,60 \mathrm{a}$ & $97,89 b$ & 12,88 & 19,22 \\
\hline
\end{tabular}

\footnotetext{
(1) Médias seguidas de mesma letra na linha, não diferem entre si pelo teste de Tukey a 5\% de probabilidade.
} 


\section{CONCLUSÕES}

Sementes embebidas em soluções com cloreto de mepiquat originam plantas com menor estatura e o efeito persiste até $31 \mathrm{DAE}$, em condições de campo, sendo a redução proporcional à concentração utilizada; reduz a altura da inserção do nó cotiledonar e não influi na altura da inserção do primeiro ramo frutífero, número total de ramos e número de ramos frutíferos;

Não há efeito da embebição de sementes com cloreto de mepiquat sobre a produção de algodão em caroço, no peso de capulho, no número de maçãs por planta e no número de maçãs na posição um;

Aplicação foliar parcelada reduz a altura da inserção do primeiro ramo produtivo, o número total de ramos, o número de ramos frutíferos e não reduz a altura da inserção do nó cotiledonar. Reduz também o número de maçãs por planta e maçãs na posição um, a massa da matéria seca de caules, de estruturas reprodutivas e de folhas.

\section{AGRADECIMENTOS}

Ao Conselho Nacional de Desenvolvimento Científico e Tecnológico (CNPq), pela concessão de bolsa ao primeiro e segundo autores.

\section{REFERÊNCIAS BIBLIOGRÁFICAS}

ALLEN, C. T.; KENNEDY, C.; ROBERTSON, B.; KHARBOUTLI, M.; BRYANT, K.; CAPPS, C.; EARNEST, L. Potential of ultra narrow row cotton in southeast Arkansas. In: BELTWIDE COTTON CONFERENCE, 1998, San Diego. Proceedings... Memphis: National Cotton Council of America, 1998. v. 2, p. 1403-1406.

ATHAYDE, M. L. F.; LAMAS, F. M. Aplicação seqüencial de cloreto de mepiquat em algodoeiro. Pesquisa Agropecuária Brasileira, Brasília, v. 34, n. 3, p. 369-375, 1999.

CORBIN JUNIOR, B. R.; FRANS, R. E. Protecting cotton (Gossypium hirsutum) from Fluometuron injury with seed protectants. Weed Science, Ames, v. 39, p. 408-411, 1991.

FURLANI JUNIOR, E.; SILVA, N. M. da; CARVALHO, L. H.; BORTOLETTO, N.; SABINO, J. C.; BOLONHEZI, D. Modos de aplicação de regulador vegetal no algodoeiro, cultivar IAC-22, em diferentes densidades populacionais e níveis de nitrogênio em cobertura. Bragantia, Campinas, v. 62 , n. 2, p. 227-233, 2003.
HODGES, H. F.; REDDY, V. R.; REDDY, K. R. Mepiquat chloride and temperature effects on photosynthesis and respiration of fruiting cotton. Crop Science, Madison, v. 31, n. 5, p. 1302-1308, 1991

KERBY, T. A. Cotton response to mepiquat chloride. Agronomy Journal, Madison, v. 72, n. 4, p. 515-518, 1985.

KERBY, T. A.; HAKE, K.; KEELEY, M. Cotton fruiting modification with mepiquat chloride. Agronomy Journal, Madison, v. 78, n. 5, p. 907-912, 1986.

LACA-BUENDIA, J. P. Efeito de doses de reguladores de crescimento no algodoeiro (Gossypium hirsutum L.). Revista Brasileira de Fisiologia Vegetal, Brasília, v. 1, n. 5, p. 109-113, 1989.

LAMAS, F. M. Estudo comparativo entre cloreto de mepiquat e cloreto de chlormequat aplicados no algodoeiro. Pesquisa Agropecuária Brasileira, Brasília, v. 36, n. 2, p. 265-272, 2001.

MARUR, C. J.; RUANO, O. A reference system for determination of developmental stages of upland cotton. Revista Brasileira de Oleaginosas e Fibrosas, Campina Grande, v. 5, n. 2, p. 313-317, 2001.

MONDINO, M. H.; PETERLIN, O. A. Diferentes criterios de decisión para la aplicación de reguladores de crecimiento y su influencia sobre el rendimiento y el crecimiento del algodón (Gossypium hirsutum L). Revista de Investigaciones Agropecuarias (RIA), Buenos Aires, v. 31, n. 2, p. 117-126, 2002.

NAGASHIMA, G. T.; MARUR, C. J.; YAMAOKA, R. S.; MIGLIORANZA, É. Desenvolvimento de plantas de algodão provenientes de sementes embebidas com cloreto de mepiquat. Pesquisa Agropecuária Brasileira, Brasília, v. 40, n. 9, p. 943-946, 2005.

NICHOLS, S. P.; SNIPES, C. E.; JONES, M. A. Evaluation of row spacing and mepiquat chloride in cotton. Journal of Cotton Science, Memphis, v. 7, n. 4, p. 148-155, 2003.

REDDY, K. R.; BOONE, M. L.; REDDY, A. R.; HODGES, H. F.; TURNER, S. B.; MCKINION, J. M. Developing and validating a model for a plant growth regulator. Agronomy Journal, Madison, v. 87, p. 1100-1105, 1995. 
RIGHI, N. R.; FERRAZ, C. A. M.; CORRÊA, D. M. Cultura. In: NEVES, O. da S. et al. Cultura e adubação do algodoeiro. São Paulo: Instituto Brasileiro da Potassa, 1965. p. 255-317.

ROSOLEN, C. A. Ecofisiologia e manejo da cultura do algodoeiro. Informações Agronômicas, Campinas, n. 95, set. 2001. Disponível em: <http://www.potafos.org/ppiweb/ brazil.nsf/\$webindex/811D27324565F55C83256B270038EA8B >. Acesso em: 24 ago. 2004.
YEATS, S. J.; CONSTABLE, G. A.; McCUMSTIE, T. Cotton growth and yield after seed treatment with mepiquat chloride in the tropical winter season. Field Crops Research, Amsterdam, v. 93, p. 122-131, 2005.

WRIGHT, D. L.; MAROIS, J. J.; WIATRAK, P. J.; SPRENKEL, R. K.; RICH, J. R.; BRECKE, B.; KATSVAIRO, T. W. Production of ultra narrow row cotton. Disponível em: <http://edis.ifas.edu/AA267>. Acesso em: 23 nov. 2005. 